\title{
Analysis of Surface Roughness, Fracture Toughness, and Weibull Characteristics of Different Framework-Veneer Dental Ceramic Assemblies after Grinding, Polishing, and Glazing
}

Pradíes, Guillermo ; Godoy-Ruiz, Laura ; Özcan, Mutlu ; Moreno-Hay, Isabel ; Martínez-Rus, Francisco

\begin{abstract}
PURPOSE To compare the surface roughness and biaxial flexural strength of dental ceramics obtained after chairside surface modification by mechanical polishing procedures, versus laboratory reglazing. MATERIALS AND METHODS Discs $(16 \times 1.5 \pm 1.6 \mathrm{~mm})(\mathrm{N}=90)$ of various frameworkveneering combinations were fabricated: D/FC: lithium disilicate/feldspathic ceramic; Z/AL: zirconium dioxide/aluminous ceramic; N/FC: noble alloy/feldspathic ceramic; N/FF: noble alloy feldspathic with fluorapatite; B/FC: base alloy/feldspathic ceramic; B/FF: base alloy/feldspathic ceramic with fluorapatite. In each group 10 specimens were ground using a diamond bur $(46 \mathrm{~m})$ and five were polished with silicone-reinforced disc polishers $(25 \mathrm{~m})$. Surface roughness (Ra) was measured using contact profilometry. After thermocycling in artificial saliva (6000 cycles, 5 to $55 \pm 5^{\circ} \mathrm{C}$ ), biaxial flexural strength was measured using "piston-on-three ball" test. The data (N) were analyzed using one-way ANOVA, Bonferroni, and Tukey's posthoc tests. Weibull distribution values were calculated. RESULTS Surface roughness was significantly higher in the ground group only $(\mathrm{p}<0.0001)$. Mean fracture toughness was significantly lower for chipping (RK: 287, HS: 22, ISO: $1099 \mathrm{MPa})$ than for total fracture $(\mathrm{p}<0.05)$, (RK: 841, HS:64, ISO: $3222 \mathrm{MPa}$ ). For chipping, Weibull distribution presented the highest shape value (m) for D/FC (3.82-5.07) and for total fracture for B/FC (3.69-4.6). CONCLUSION Chairside surface polishing restored veneer ceramic roughness and mechanical strength to the level of glazing. Feldspathic ceramic with fluorapatite presented better polishing results than conventional feldspathic ceramic did. Ceramic fused to metal was more resistant than lithium disilicate or zirconium dioxide framework-veneer assemblies. Lithium disilicate framework veneered with feldspathic ceramic presented more durability against chipping. CLINICAL IMPLICATIONS After chairside occlusal modifications in the surfaces of cemented all-ceramic or fused-to-metal FDPs, mechanical polishing procedures should always be carried out.
\end{abstract}

DOI: https://doi.org/10.1111/jopr.12653

Posted at the Zurich Open Repository and Archive, University of Zurich

ZORA URL: https://doi.org/10.5167/uzh-183040

Journal Article

Accepted Version

Originally published at:

Pradíes, Guillermo; Godoy-Ruiz, Laura; Özcan, Mutlu; Moreno-Hay, Isabel; Martínez-Rus, Francisco (2019). Analysis of Surface Roughness, Fracture Toughness, and Weibull Characteristics of Different Framework-Veneer Dental Ceramic Assemblies after Grinding, Polishing, and Glazing. Journal of Prosthodontics, 28(1):e216-e221. 
DOI: https://doi.org/10.1111/jopr.12653 
Analysis of the Surface Roughness, Fracture Toughness and Weibull Characteristics of Different Framework/Veneer Dental Ceramic Assemblies After Grinding, Polishing and Glazing

Laura Godoy Ruiz, DDS, PhD,1 Francisco Martínez Rus, DDS, PhD,1 Mutlu Özcan, DDS, DMD, PhD,1 I Moreno, DDS, PhD,1 Guillermo Pradíes, DDS, $\mathrm{PhD}_{2}$

${ }_{1}$ Complutense University of Madrid, Department of Buccofacial Prostheses, Faculty of Dentistry, Madrid, Spain

${ }_{2}$ University of Zurich, Dental Materials Unit, Center for Dental and Oral Medicine, Clinic for Fixed and Removable Prosthodontics and Dental Materials Science, Zurich, Switzerland

Short title: Influence of grinding, polishing and glazing on ceramic systems

*Correspondance:

Prof. Dr. Mutlu Özcan

University of Zurich

Center for Dental and Oral Medicine

Clinic for Fixed and Removable Prosthodontics and Dental Materials Science

Dental Materials Unit

Plattenstrasse 11

$\mathrm{CH}$ 8032, Zurich, Switzerland

E-mail: mutluozcan@hotmail.com 


\section{Abstract}

Purpose: After cementation of fixed dental prosthesis, slight modifications of the occlusal contacts are commonly required in specific areas to eliminate premature contacts with the adjacent or antagonist teeth. This study compared the surface roughness and biaxial flexural strength of dental ceramics after chairside surface modification procedures versus laboratory reglazing.

Materials and Methods: Discs $(16 \times 1.5 \pm 1.6 \mathrm{~mm})(\mathrm{N}=90)$ of various framework-veneering combinations were fabricated: a) D/FC: Lithium disilicate (IPS e.max Press)/Conventional feldspathic ceramic (IPS e.max Ceram), b) Z/AL: Zirconium dioxide (Lava)/Conventional aluminous (Lava Ceram), c) N/FC: Noble alloy (Cerapall)/feldspathic ceramic (IPS InLine), d) N/FF: Noble alloy (Cerapall)/Feldspathic with fluorapatite (IPS d.Sign), e) B/FC: Base alloy (Tilite)/Conventional feldspathic (IPS InLine), f) B/FF: Base alloy (Tilite)/Feldspathic ceramic with fluorapatite (IPS d.Sign). In each group 10 specimens were ground using a fine grit flame shaped diamond bur $(46 \mu \mathrm{m})$ and five specimens were randomly assigned for polishing with silicone diamond reinforced disc shaped polishers $(25 \mu \mathrm{m})$. Surface roughness $(\mathrm{Ra})$ of each specimen was measured using contact profilometry. After thermocycling in artificial saliva ( 6000 cycles, 5 to $55 \pm 5^{\circ} \mathrm{C}$ ), biaxial flexural strength was measured using "piston-on-three ball" test. The data $(\mathrm{N})$ were analyzed using 1-way ANOVA. Weibull distribution values including the Weibull modulus $(m)$, characteristic strength $(0)$, and probability of failure at $5 \%(0.05), 1 \%(0.01)$, correlation coefficient were calculated.

Results: Surface roughness was the highest in the ground group $(P=0.000)$. No significant differences were found between glazed and polished specimens $(p=0.83)$. The polished specimens showed significantly higher biaxial flexural strength than those of glazed and ground specimens $(p=0.003)$. Weibull distribution presented lower shape value $(m)$ of KE ( $m=5.48$; Cl. 3.5-8.6) compared to LC ( $m=7.68$; Cl. 5.2-11.3).

Conclusion: Chair side surface polishing procedures could restore the surface roughness of veneer ceramic and mechanical strength to the level of glazing. Ceramic fused to metal groups, and specifically with base alloy, was mechanically more resistant than lithium disilicate or zirconium dioxide framework-veneer 
assemblies. Feldspathic ceramic with fluorapatite presented better polishing results than conventional feldspathic ceramic.

\section{Keywords}

Ceramic, Glaze; Finishing; Fracture toughness, Polishing; Surface roughness. 


\section{Introduction}

Ceramics today are widely used in most fixed dental prosthesis (FDP) because of their favorable optical properties, durability and biocompatibility. 1 Traditionally, ceramics have been used as veneering material on metallic frameworks that provide the required physical properties. Metals used in prosthetic dentistry are principally gold or palladium based noble alloys and base alloys such as cobalt-chrome or chrome-nickel. Due to higher translucency and thereby better optical properties, the current trend is the use of metal-free, all ceramic systems especially for anterior FDPs. Most of the all-ceramic framework options are heat-pressed or CAD/CAM processed being mainly composed of lithium disilicate or zirconium dioxide. Feldsphatic ceramics are still being used as veneering material due to their high translucency similar to natural teeth.2 The bonding between veneering ceramic and metal in porcelain-fused-to-metal FDPs has been extensively studied. The strength of this bonding is due to the formation of an oxide layer, mechanical and compressiverheological interlocking between both components. However, ceramic-to-ceramic bond is mainly chemical bonding because of the formation of new crystal phases between different ceramic framework and the veneering ceramic. Unfortunately, particularly zirconium dioxide framework-veneer bonding remains to be a clinical problem where the incidence of delamination or chipping has been reported up to $25 \%$ after 31 months.3-5 One of the reasons for such failures was associated with the roughness of the veneering ceramic.x Biomechanical properties and surfaces of materials can be affected by the aggressive oral milieu and the presence of saliva, acidic drinks and plaque which alter the surface roughness of ceramics over time.6,7 Rough ceramic surfaces could also occur as a result of technical procedures during the workflow of prosthetic work. Several factors may influence the final shape and dimensions of the FDP, such as impression materials, impression techniques and laboratory procedures. Also, cement thickness may yield to premature contacts after cementation of the FDP that needs to be removed using dental burs in order to achieve proper contact with the adjacent or antagonist teeth. Clinically, the grain size of the burs, pressure, speed and duration dictates the roughness of the veneering ceramic. Such intraoral alterations reduces the ceramic thickness, removes the glazed layer, revealing a rougher surface which consequently decreases 
the fracture toughness of the restoration, $, 8,9$ increases the wear of opposing restoration and/or teeth enamel 10,11 and promotes pigmentation of the ceramic. 6 When premature contacts are eliminated prior to cementation, the FDP could be autoglazed or overglazed in the dental laboratory.7 However, after cementation, such adjustments needs to be repolished manually. Several studies showed that appropriately polished ceramic surface can be achieved clinically by means of polishing without necessitating glazing afterwards in the laboratory.12-14 Other studies also reported that smoother surfaces could be obtained with chairside grinding and polishing similar to autoglazed surfaces.15,16 Nevertheless, fracture toughness of the veneering ceramics could be affected by such procedures depending on the chemistry of the ceramic.

The objectives of this study therefore were to compare the surface roughness and fracture toughness of framework-veneer ceramic assemblies after chairside grinding and polishing procedures versus laboratory glazing techniques. The null hypothesis tested was that polishing and glazing procedures would not affect surface roughness and fracture toughness of different ceramics.

\section{Materials and Methods}

\section{Preparation of specimens}

Discs shaped specimens (diameter: $16 \mathrm{~mm}$, thickness: $1.5 \pm 1.6 \mathrm{~mm})(\mathrm{N}=90)$ of various framework-veneering combinations were fabricated after processing wax patterns, investment and casting except for the zirconium dioxide framework for which CAD/CAM processing was used. Specimens were divided into six groups, depending on the combination of materials (Table 1):

Group D/FC: Framework disks were made through lost-wax casting and press technology using a low-fusing lithium disilicate glass-ceramic. Wax pattern was made (K2 exact, Bredent GmbH\&Co.KG, City, Germany) and invested (IPS Press VEST, Ivoclar Vivadent, Schaan, Liechtenstein) and finally wax was eliminated in the preheating furnace (KaVo mod. 5522, Biberach, Germany). Manufacturer's instructions were strictly followed in terms of time and temperature during operating the furnace (Programat EP 600, Ivoclar, Vivadent). After cooling for $60 \mathrm{~min}$ at room temperature, frameworks were veneered with the conventional 
feldespathic ceramic using layering technique, in two layers and fired (ProgramatEP 500, Ivoclar, Vivadent). Finally, specimens were overglazed (IPS e.max Ceram Glaze, Ivoclar, Vivadent) and no mechanical polishing was performed.

Group Z/AL: In this group, framework discs were obtained from presintered partially yttria stabilized zirconia blocks with CAD/CAM technology (Lava CNC 240, 3M ESPE, Seefeld, Germany). Then, highly aluminous feldspathic veneering ceramic was applied employing layering technique and overglazed (Lava, 3M ESPE) following manufacturer's instructions. No mechanical polishing was realized.

Group N/FC: Noble alloy framework discs were fabricated by lost-wax technique. After wax pattern was made (BEGO Dental GmbH\&Co.KG), investment and casting process were carried out (GC Vest Premium, GC, Tokyo, Japan) and finally wax was eliminated in the preheating furnace (KaVo mod. 5522, Biberach, Germany). The alloy was heated at the melting point according to manufacturer's recommendations for the casting procedures (Ducatro, Ugin Dentaire, Seyssins, France). Specimens were cleaned by airborne particle abrasion and placed in the furnace for oxidation (Programat 500). Then, veneering ceramic was applied by layering technique where two layers of opaque and two layers of dentin ceramic were used. Specimens were then overglazed with a pre-mixed syringe (Ivoclar, Vivadent).

Group N/FF: For this group, the same procedures were followed as decribed for the N/FC group but for veneering feldspathic with fluorapatite ceramic was used where two layers of opaque and two layers of dentin ceramic were used. Specimens were then overglazed with a pre-mixed syringe (Ivoclar, Vivadent).

Group B/FC: In this group, identical fabrication procedures were followed as for N/FC but regarding the manufacturer's specifications for the base alloy.

Group B/FF: In this group, identical fabrication procedures were followed as for B/FC group for the metal frameworks and veneering was similar as described for N/FF group.

\section{Surface roughness analysis}

The specimens were cleaned ultrasonically in distilled water and dried. Surface roughness was measured using contact profilometeter (Perthometer M1, Mahr, Göttingen, Germany) where two roughness 
parameters, $R_{a}$ (average roughness value) and $R_{z}$ (average of five maximum peaks of roughness value), were registered in microns. These measurements were considered as baseline measurements. To rule out the weight loss associated with contact profilometry, specimens were weighed in a digital balance (PCB BSH 1000, Germany) before and after roughness measurements and no weight loss was identified. Then, in each group 10 specimens were subjected to manual grinding using a fine grit flame shaped diamond bur (46 m) (DZ92, Lot № 041105 Drendel+Zweiling, Berlin, Germany) at high speed (450000 rpm) under watercooling. One operator performed grinding using a new bur for each group and supporting the specimens on a horizontal surface for the duration of $30 \mathrm{~s}$. Surface roughness was measured again considering $R_{a} a n d R_{z}$ parameters. Thereafter, five specimens from each group were manually polished using silicone diamond reinforced $(25 \mu \mathrm{m})$ disc shaped polishers (OptraFine F, Ivoclar Vivadent) at low speed (135000) under watercooling. Again, one operator performed polishing using a new polisher for each group under the same conditions as for grinding and surface roughness was measured.

Subsequently, the specimens were thermocycled (pat. № P201200882 Complutense University of Madrid, Spain) for 6000 cycles between $5 \pm 5^{\circ} \mathrm{C}$ and $55 \pm 5^{\circ} \mathrm{C}$ with dwell time of $20 \mathrm{~s}$ in each bath and $3 \mathrm{~s}$ immersion in artificial saliva.

\section{Biaxial flexural strength analysis}

Biaxial flexural strength was measured by means of "piston-on-three ball" biaxial flexural strength test (Autograph AG-X, Shimadzu, Kyoto, Japan) with the framework facing the piston (Fig. 1). First, fracture toughness values were recorded at the first peak on the stress-strain curve, also called chipping, second, at the veneer fracture (Fig. 3). Biaxial flexural stregth was calculated according to Roark's17 formula (a), Roark's17 formula modified by Hsueh et al. 18-20 (b) and ISO 6782 for multilayered materials(c):

$$
\delta=\frac{E_{2}\left(z-z_{n}^{*}\right) P}{8 \pi\left(1-v_{2}\right) D^{*}}\left\{2 \ln \left(\frac{a}{b}\right)+\frac{(1-v)\left(a^{2}-b^{2}\right)}{(1+v) R^{2}}\right\}
$$




$$
\begin{aligned}
& z_{n}^{*}=\frac{E_{1} t_{1}^{2} / 2\left(1-v_{1}^{2}\right)+E_{2} t_{2}^{2} / 2\left(1-v_{2}^{2}\right)+E_{2} t_{1} t_{2} /\left(1-v_{2}^{2}\right)}{E_{1} t_{1} /\left(1-v_{1}^{2}\right)+E_{2} t_{2} /\left(1-v_{2}^{2}\right)}(\mathrm{b}) \\
& D^{*}=\frac{E_{1} t_{1}^{3}}{3\left(1-v_{2}^{2}\right)}+\frac{E_{2} t_{2}^{3}}{3\left(1-v_{2}^{2}\right)}+\frac{E_{2} t_{1} t_{2}\left(t_{1}+t_{2}\right)}{1-v_{2}^{2}}-\frac{\left[E_{1} t_{1}^{2} /\left(2\left(1-v_{1}^{2}\right)\right)+E_{2} t_{2}^{2} / 2\left(1-v_{2}^{2}\right)+E_{2} t_{1} t_{2} /\left(1-v_{2}^{2}\right)\right]^{2}}{E_{1} t_{1} /\left(1-v_{1}^{2}\right)+E_{2} t_{2} /\left(1-v_{2}^{2}\right)} \text { (c) } \\
& v=\frac{v_{1} t_{1}+v_{2} t_{2}}{t_{1}+t_{2}}
\end{aligned}
$$

where, $P$ is stress in Newtons, $t_{1}$ or $t_{a}$ is the veneering ceramic thickness in $\mathrm{mm}$, $t_{2}$ or $t_{b}$ is the framework thickness in $\mathrm{mm}, a$ is the radius of the supporting area, $b$ is the radius of the loaded area in $\mathrm{mm}, r$ is the radius of the specimen in $\mathrm{mm}, \sqrt{ }_{1}$ or $\sqrt{a}_{a}$ is the Poisson ratio of the veneering ceramic, $\sqrt{ }_{2}$ or $\sqrt{b}_{b}$ is the Poisson ratio of the framework material, $V_{e}$ is the equivalent Poisson ratio, $E_{1}$ or $E_{a}$ is the elastic modulus of veneering ceramic, $E_{2}$ or $E_{b}$ is the elastic modulus of framework material.

\section{Statistical analysis}

Statistical analysis was performed with SPSS Statistics for Windows Version 19 (SPSS, IBM, Armonk, New York, USA). Pearson's correlation test, Spearman's Rho and repeated measures analysis of variance were performed between $R_{a}$ and $R_{z}$ values. Due to significant difference in groups $(p<0.01)$, only $R_{a}$ values were considered for the analysis. Likewise, three different formulas applied to fracture toughness showed identical results, thus Roark`s formula modified by Hsueh et al. was chosen for the statistical analysis. Data were analyzed using one-way analysis of variance (ANOVA) followed by Bonferroni's and Tukey's post hoc tests for multiple comparisons. Weibull distribution values including the Weibull modulus $(m)$, characteristic strength (0), probability of failure at $5 \%(0.05), 1 \%(0.01)$, correlation coefficient were calculated:

$$
\ln \ln \frac{1}{1-F_{\left(\sigma_{c}\right)}}=m \ln \sigma_{c}-m \ln \sigma_{0}
$$

$P$ values less than 0.01 were considered to be statistically significant in all tests. 


\section{Results}

The repeated measures analysis of variance showed significant differences between the three surface treatments $(F(2,58)=53.197 ; p<0.0001)$. The surface roughness values $(R a)$ depending on the surface treatment were $1.9 \pm 0.5 \mu \mathrm{m}$ for the glazed, $3.5 \pm 0.7 \mu \mathrm{m}$ for the ground, and $1.7 \pm 1.1 \mu \mathrm{m}$ for the polished specimens. Glazed and polished groups did not show significant difference $(p>0.01)$ being significantly lower than the ground specimens (Bonferroni test) $(p<0.0001)$ (Table 2).

Differences between the combination of material groups with a two-factor analysis of variance (frameworkveneer materials) resulted in no statistically significant differences between framework materials $(F(2,88)=0.049 ; p=0.826)$. However, statistically significant differences were found between veneer materials $(F(2,88)=13.58 ; p<0.001)$, specifically between the conventional feldspathic veneer (IPS Inline) and feldspathic with fluorapatite (IPS d.Sign) with lowest Ra values for the latter (Tukey`s).

Three formulas cited above showed high degree of correlation according to Pearson coefficient and Spearman's Rho $(p<0.01)$. The biaxial flexural strength values at chipping were $25.6 \pm 2.55 \mathrm{MPa}$ for glazed, 16.3 \pm 7.9 MPa for ground, and $61.6 \pm 6.33 \mathrm{MPa}$ for polished group. Biaxial flexural strength values were

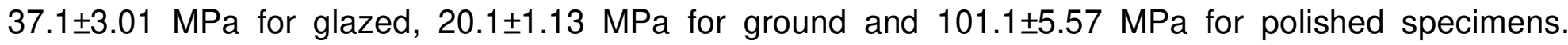
Independent samples analysis of variance showed statistically significant differences between the three surface treatments for biaxial flexural strength at both chipping $(F(2,86)=9.48 ; p<0.0001)$ and total veneer fracture $(F(2,86)=34.72 ; p<0.0001)$. Polished specimens after grinding, showed higher values than those of other groups (Fig. 4, Table 3).

The two-factor analysis of variance (surface treatment and materials) showed statistically significant differences between groups for biaxial flexural strength at both chipping $(F(5,83)=8.42 ; p<0.0001)$ and total veneer fracture $(F(5,83)=7.41 ; p<0.0001)$. Veneer ceramic type did not affect biaxial flexural strength at chipping $\left(F_{(3,85)}=2.54 ; p=0.062\right)$ but did for total fracture $\left(F_{(5,83)}=9.57 ; p<0.0001\right)$. Veneers of all-ceramic specimens were less resistant than metal-ceramic ones (Fig. 5). On the other hand, framework material affected both chipping $\left(F_{(3,85)}=12.26 ; p<0.0001\right)$ and biaxial flexural strength $\left(F_{(5,83)}=10.1 ; p<0.0001\right)$. Related 
to chipping, base alloy proved to be the most resistant one than noble alloy $(p<0.01)$ and ceramic framework. Lithium disilicate and zirconium dioxide framework materials did not show significant difference for chipping $(p=0.535)$ and total fracture $(p=0.11)$ but their biaxial flexural strength was significantly less than those of base and noble alloys $(p<0.003)$ (Fig. 6$)$.

Weibull distribution presented lower shape value $(m)$ of $\mathrm{KE}(m=5.48$; $\mathrm{Cl}$. $3.5-8.6)$ compared to LC $(m=7.68 ; \mathrm{Cl} .5 .2-11.3)$. Characteristic strengths (0) (KE: $1784.9 \mathrm{~N} ; \mathrm{LC}: 1712.1 \mathrm{~N})$ were higher than probability

of failure at 5\% (0.05) (KE: $1038.1 \mathrm{~N}$; LC: $1163.4 \mathrm{~N})$ followed by 1\% (0.01) (KE: $771 \mathrm{~N}$; LC: $941.1 \mathrm{~N})$, with a correlation coefficient of 0.966 for KE and 0.924 for LC (Table 1, Fig. 2).

\section{Discussion}

Clinical practice often necessitates the adjustment of ceramics before or even after cementation of FDPs to establish adequate contact with the opposing and/or adjacent teeth. These corrections performed by rotating instruments produce rougher surfaces, promote plaque accumulation,22 decrease fracture toughness, $, 22,23$ and increase the wear of the opposing natural teeth as well as restorative surfaces,10,11 Re-glazing the ground ceramic restorations may increase chair-side time 24 and it is not always feasible as some adjustments can only be made after cementation.2,8 Thus, it seems necessary to find out whether it is possible to obtain smooth ceramic surfaces similar to glazed surfaces after clinical adjustments. Smooth surfaces would also prevent possible chipping or fracture of the veneering ceramic.

This study was undertaken to compare the surface roughness and biaxial flexural strength of frameworkveneer ceramic assemblies after chairside grinding and polishing procedures versus laboratory glazing techniques. Based on the results of obtained, the null hypothesis tested was that polishing and glazing procedures would not affect surface roughness and biaxial flexural strength of different ceramics could be rejected. 
The simulated chair-side ceramic grinding with fine grit flame shaped diamond bur resulted in mean roughness value of $3.5 \pm 0.72 \mu \mathrm{m}$ similar to previous studies, 7,25 being significantly higher than glazed surfaces. When ceramic surfaces were polished using silicone diamond reinforced disc shaped polishers, surface roughness values were $1.67 \pm 1.08 \mu \mathrm{m}$ comparable to those of the glazed ones $(1.9 \pm 0.45 \mu \mathrm{m})$. These results are less than those of other reports.12-14 In this study, only one polishing bur was used to polish the surfaces and no polishing paste was utilized in order to reduce number of steps and materials. Yet, the results were similar to those investigations where polishing kits were used that involved a sequence of discs or polishing pastes.12-14 Not only the surface coating of the burs but also the duration of the polishing dictates the roughness of the ceramic surface. In this study, this procedure was practiced for $30 \mathrm{~s}$ which is less than other studies23,24 and longer than others.25-27

The biaxial flexural strength results should be interpreted with caution. Biaxial flexural strength data for ceramics provided by the manufacturers or ISO 6872 typically concern only monolayer ceramic meaning that framework material is not taken into account. In fact, mechanical properties of the framework-veneer interface play an important role in the mechanical behaviour of the veneer. Similarly, previous studies considered framework materials and veneer ceramic separately when reporting their biaxial flexural strength.26,27 Furthermore, the Roark`s formula modified by Hsueh et al.18-20 is not frequently used. Nevertheless, this formula seems to be the most appropriate for testing multilayer ceramics and due to the high correlation observed with Roark's and ISO 6872 formulas was selected to analyze the results of this study.

Chipping and biaxial flexural strength values (MPa) were $28.6 \pm 2.55$ and $37.1 \pm 3.08$ for glazed, $16.27 \pm 7.9$ and $20.9 \pm 1.13$ for ground $61.6 \pm 6.33$ and $101.9 \pm 5.57$ for polished specimens after grinding, respectively. No differences were found between glazed and ground groups but polished group showed significantly greater values. Based on these results, it can be stated that grinding simulating chairside adjustments do not decrease biaxial flexural strength but polishing after grinding increases the mechanical properties of the tested materials. One explanation for the increased biaxial flexural strength after polishing could be due to 
the heat generated from surface friction between polisher and ceramic produced during compressive forces. 8,15,28-30 ISO 6782 suggests biaxial flexural strength of $100 \mathrm{MPa}$ acceptable for dental ceramics. However, it seems most appropriate to use metal-ceramic restorations with fracture toughness between 400 and 600 $\mathrm{MPa}$ as reference point.2

Biaxial flexural strength values were significantly affected depending on the framework and veneering ceramics. Group B/FC was the most resistant to chipping and groups with metal framework (B/FC, B/FF, $\mathrm{N} / \mathrm{FC}$ and N/FF) were more resistant compared to those of all-ceramic frameworks (D/FC, Z/AL). The favourable results for the metals could be explained on the grounds that bonding between metal-to-ceramic was more durable than in ceramic-to-ceramic due to the oxide layer. Correspondingly, the base alloy having the highest oxidation potential may explain the highest values of toughness for chipping in this group. Other inherent properties such as thermal conductivity, thermal expansion coefficient or wettability of the ceramic could have also influenced the results.

Although the presence of saliva has been simulated using artificial saliva in thermocycling, the lack of occlusal forces during aging process could be considered as the limitation of this study. Thus, incidence of clinical failures after good documentation of the occlusal adjustments is of importance at this stage to verify the findings of this study. Also, new monolithic all-ceramic systems should be evaluated clinically whether their polishing capacity produces less wear in opposing teeth. 31

\section{Conclusions}

From this study, the following could be concluded: 
1- Surface roughness of veneering ceramics was the highest after grinding with fine grit flame shaped diamond bur $(46 \mu \mathrm{m})$ and the lowest after polishing with silicone diamond reinforced disc shaped polishers $(25 \mu \mathrm{m})$, and glazing.

2- Feldspathic ceramic with fluorapatite presented better polishing results than conventional feldspathic ceramic.

3- Grinding, polishing and glazing did not affect the fracture toughness indicating that chair side surface polishing procedures could restore the surface roughness and mechanical strength to the level of glazing.

4- Ceramic fused to metal groups, and specifically with base alloy, was mechanically more resistant than lithium disilicate or zirconium dioxide framework-veneer assemblies.

\section{Acklowledgements}

The authors greatly acknowledge CDTs Lorenzo del Río for their contribution to the creation of the specimens and José Batolomé, Antonio de Aza y Manuel Belmonte (CSIC, Madrid, Spain) for their collaboration with mechanical tests

\section{Conflict of interest}

The authors did not have any commercial interest in any of the materials used in this study.

\section{References}


1. Nakamura T, Dei N, Kojima T, et al: Marginal and internal fit of Cerec 3 CAD/CAM all-ceramic crowns. Int J Prosthodont 2003;16:244-248.

2. Souza RO, Özcan M, Pavanelli CA, et al: Marginal and internal discrepancies related to margin design of ceramic crowns fabricated by a CAD/CAM system. J Prosthodont 2012;21:94-100.

3. Aboushelib MN, Kleverlaan CJ, Feilzer AJ. Microtensile bond strength of different components of core veneered all-ceramic restorations. Part II: Zirconia veneering ceramics. Dent Mater 2006; 22(9): 857-63.

4. Sailer I, Feher A, Filser F. Prospective clinical study of zirconia posterior fixed partial dentures: 3-year follow up. Quintessence Int 2006; 37: 685-93.

5. Raigrodski AJ, Chiche GJ, Potiket N. The efficacy of posterior three-unit zirconium oxide-based ceramic fixed partial dental prostheses: a prospective clinical pilot study. J Prosthet Dent 2006; 96: 237-44.

6. Tholt B, Miranda-Junior WG, Prioli R, Thompson J, Oda M. Surface roughness in ceramics with different finishing techniques using atomic force microscope and profilometer. Operative dentistry 2006; 31(4): 442-49.

7. Bollen CML, Lambrechts $P$, Quirynen M. Comparison of surface roughness of oral hard materials to the threshold surface roughness for bacterial plaque retention: A review of the literature. Dent Mater 1997; 13: 258-269.

8. Al-Wahadni A. "An in vitro investigation into the surface roughness of 2 glazed, unglazed, and refinished ceramic material". Quintessence Int 2006; 37:311-17.

9. Sarac D, Sarac YS, Yuzbasioglu E, Bal S. The effects of porcelain polishing systems on the color and surface texture of feldespathic porcelain. J Proshet Dent 2006; 96: 122-8.

10. Heintze SD, Cavalleri A, Forjanic M, Zellweger G, Rousson V. Wear of ceramic and antagonist-A sistematic evaluation of influencing factors in vitro. Dent Mater 2008; 24 (24):433-449.

11. Oh WS, Delong R, Anusavice KJ. Factors affecting enamel and ceramic wear: A literature review. J Prosthet Dent 2002; 87: 451-9.

12. Suputtamongkol K. et al. Clinical perfomance and wear characteristics of veneered lithia-disilicate-based ceramic crowns. Dent Mater. 2008; 24(5): 667673. 
13. Wright MD, Masri R, Driscoll CF, Romberg E, Thompson GA, Runyan DA. Comparison of three systems for the polishing of an ultra-low fusing dental porcelain. J Prosthet Dent 2004; 92: 486-90.

14. Magne P, Oh WS, Pintado MR, DeLong R. Wear of enamel and veneering ceramics after laboratory and chairside finishing procedures. J Prosthet Dent 1999; 82: 669-79.

15. Giordano R, Cima M, Pober R. Effect of surface finish on the flexural strenghth of feldespathic and aluminous dental ceramics. Int J Prosthodont 1995; 8:31119.

16. Hsueh $\mathrm{CH}$, Thompson GA, Jadaan OM, Wereszczak AA, Becher PF. Analysis of layer-thickness effects in bilayered dental ceramics subjected to thermal stresses and ring-on-ring tests. Dent Mat 2008; 24: 9-17.

17. Roark JR, Young WC, Budynas RG. Roark's formulas for stress \& strain. $5^{\underline{a}}$ Edición. New York. McGraw-Hill; 1986. p.377-9.

18. Hsueh $\mathrm{CH}$, Lutrell $\mathrm{CR}$, Becher PF. Analysis of multilayered dental ceramics subjected to biaxial flexure tests. Dent Mater 2006; 22: 460-469.

19. Hsueh $\mathrm{CH}$, Thompson GA. Appraisal of formulas for stresses in bilayered dental ceramics subjected to biaxial moment loading. J Dent 2007; 35: 600-606.

20. Hsueh $\mathrm{CH}$, Kelly JR. Simple solutions of multilayered discs subjected to biaxial moment loading. Dent Mater 2009; 25: 506-513.

21. ISO 6782. Ceramics. 2008

22. Quirynen M. Bollen CML. The influence of surface roughness and surface-free energy on supra- and subgingival plaque formation in man. $\mathrm{J}$ Clin periodontolo 1995; 22: 1-14.

23. Bessing $\mathrm{C}$, Wiktorsson A. Comparison of two different methods of polishing porcelain. Scan J Dent Res 1983; 91: 482-7.

24. Bollen CML, Lambrechts $P$, Quirynen M. Comparison of surface roughness of oral hard materials to the threshold surface roughness for bacterial plaque retention: A review of the literature. Dent Mater 1997; 13: 258-269.

25. Ahmad R Morgano SM, Wu BM, Giordano RA. An evaluation of the effects of handpiece speed, abrasive characteristics, and polishing load on the flexural strength of polished ceramics. J Prosthet Dent 2005; 94: 421-9.

26. Cho MS, Lee YK, Lim BS, Lim YJ. Changes in optical properties of enamel porcelain after repeated external staining. J Prosthet Dent 2006; 95: 437-43.

27. Fischer J, Stawarczyk B, Hämmerle CHF. Flexural strength of veneering ceramics for zirconia. J Dentistry 2008; 36: 316-321. 
28. Yilmaz H, Aydin C, Gul BE. Flexural strength and fracture toughness of dental core ceramics. J Prosthet Dent 2007; 98: 120-8.

29. Alkhiary YM, Morgano SM, Giordano RA. Effects of acid hydrolisis and mechanical polishing on surface residual stresses of low-fusing dental ceramics. J Prosthetic Dent 2003; 90(2): 133-141.

30. Amer R, Kürklü $\mathrm{D}$, Johnston $\mathrm{W}$. Effect of simulated mastication on the surface roughness of three ceramic systems. J Prosthet Dent 2015; 5:121-3.

\section{Captions to tables and legends:}




\section{Tables:}

Table 1. Framework and veneering materials, manufacturers and abbreviations of groups.

Table 2. Surface Roughness $(\mathrm{Ra})(\mu \mathrm{m})$ of veneering materials after grinding, polishing or glazing. See Table 1 for group abbreviations.

Table 3. Fracture toughness $(\mathrm{MPa})$ of framework-veneering ceramic combinations at chipping and total fracture. See Table 1 for group abbreviations.

\section{Figures:}

Fig. 1 "Piston-on-three ball" biaxial flexural strength test where specimens were placed with the framework facing the piston.

Fig. 2 Representative stress-strain graphic of metal-ceramic assembly where the first peak was considered as "chipping" (373 N) in the veneer ceramic.

Fig. 3 Boxplot for fracture toughness of specimens regarding the surface treatment factor where highest values were obtained for the polished group.

Fig. 4 Boxplot for fracture toughness of specimens regarding the veneering material where metal-ceramic assemblies showed higher values than all-ceramic groups.

Fig. 5 Boxplot for fracture toughness of specimens regarding the framework material where metals showed higher values than all-ceramic groups.

Tables: 
Lithium disilicate

D/FC

Z/AL

N/FC

N/FF

B/FC

B/FF
(IPS e.max Press, Ivoclar Vivadent, Schaan, Liechtenstein)

Zirconium dioxide

(Lava, 3M ESPE, Seefeld, Germany)

Noble alloy

(Cerapall 6, Metalor, Attleboro, USA)

Noble alloy

(Cerapall 6, Metalor)

Base alloy

(Tilite, Talladium España, Lleida, Spain)

Base alloy

(Tilite,Talladium España)
Conventional feldspathic ceramic

(IPS e.max Ceram, Ivoclar Vivadent)

Feldspathic ceramic with high alumina

(Lava Ceram, 3M ESPE)

Conventional feldspathic ceramic (IPS InLine, Ivoclar Vivadent)

Feldspathic ceramic with fluorapatite (IPS d.Sign, Ivoclar Vivadent)

Conventional feldspathic ceramic (IPS InLine, Ivoclar Vivadent)

Feldspathic ceramic with fluorapatite (IPS d.Sign, Ivoclar Vivadent)

Table 1. Framework and veneering materials, manufacturers and abbreviations of groups. 


\begin{tabular}{|c|c|c|c|c|}
\hline Experimental Groups & $\mathbf{n}$ & Ground & Polished & Glazed \\
\hline $\begin{array}{c}\text { Surface Roughness (Ra) } \\
(\mu \mathrm{m})\end{array}$ & 15 & $3.575 \pm 0.694 \mathrm{a}$ & $1.735 \pm 0.521$ & $1.819 \pm 0.297$ \\
\hline D/FC & 15 & $3.295 \pm 0.647 \mathrm{a}$ & $1.629 \pm 0.810$ & $1.913 \pm 0.531$ \\
\hline Z/AL & 15 & $3.773 \pm 0.938 \mathrm{a}$ & $2.597 \pm 2.133$ & $2.076 \pm 0.437$ \\
\hline N/FC & 15 & $3.207 \pm 0.325 \mathrm{~b}$ & $0.852 \pm 0.183$ & $1.269 \pm 0.492$ \\
\hline N/FF & 15 & $3.701 \pm 1.07 \mathrm{a}$ & $1.759 \pm 0.901$ & $1.961 \pm 0.532$ \\
\hline B/FC & 15 & $3.511 \pm 0.662 \mathrm{~b}$ & $1.605 \pm 0.489$ & $1.380 \pm 0.303$ \\
\hline B/FF & & & & \\
\hline
\end{tabular}

Table 2. Surface Roughness $(\mathrm{Ra})(\mu \mathrm{m})$ of veneering materials after grinding, polishing or glazing. See Table 1 for group abbreviations.

$\left(^{*}\right)$ Different letters indicate statistically differences between experimental groups $(p \leq 0,05)$. 


\begin{tabular}{|c|c|c|c|}
\hline Experimental Groups & $\mathbf{n}$ & Chipping & Total fracture \\
\hline Fracture toughness (MPa) & & Mean (SD) * & Mean (SD) * \\
\hline D/FC & 15 & $13.64 \pm 6.74 \mathrm{a}$ & $13.9 \pm 6.60 \mathrm{a}$ \\
\hline Z/AL & 15 & $27.18 \pm 3.46 \mathrm{a}, \mathrm{c}$ & $37.50 \pm 3.12_{\mathrm{a}, \mathrm{b}}$ \\
\hline N/FC & 15 & $24.27 \pm 1.04 \mathrm{a}, \mathrm{c}$ & $75.65 \pm 4.16 \mathrm{c}$ \\
\hline N/FF & 15 & $24.35 \pm 1.04 \mathrm{a}, \mathrm{c}$ & $49.86 \pm 3.79 \mathrm{~b}, \mathrm{c}$ \\
\hline B/FC & 15 & $69.07 \pm 6.07 \mathrm{~b}$ & $69.07 \pm 6.07 \mathrm{~b}, \mathrm{c}$ \\
\hline B/FF & 15 & $48.72 \pm 5.37 \mathrm{~b}, \mathrm{c}$ & $62.19 \pm 6.63_{\mathrm{b}, \mathrm{c}}$ \\
\hline
\end{tabular}

Table 3. Fracture toughness (MPa) of framework-veneering ceramic combinations at chipping and total fracture. See Table 1 for group abbreviations.

$\left({ }^{*}\right)$ Different letters indicate statistically differences between experimental groups $(p \leq 0,05)$. 


\section{Figures:}

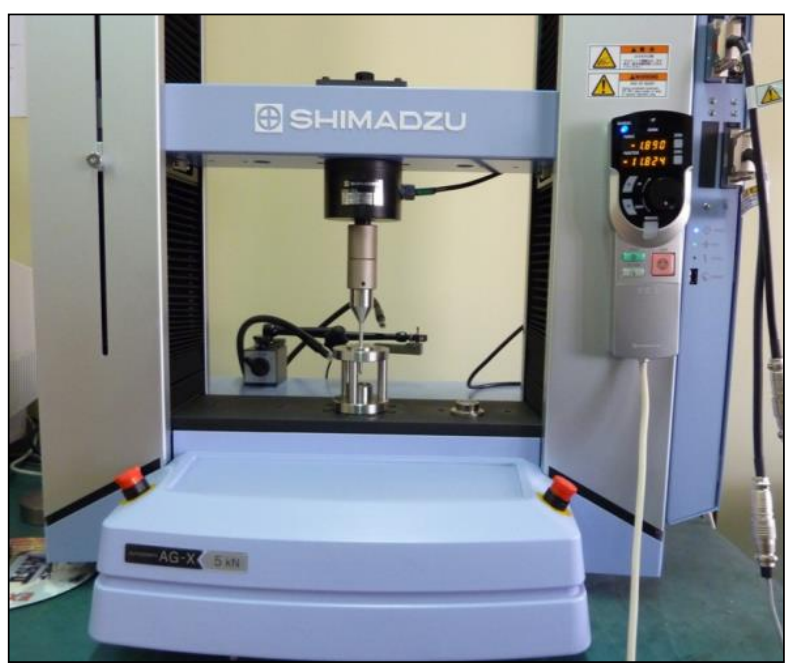

Fig. 1 "Piston-on-three ball" biaxial flexural strength test where specimens were placed with the framework facing the piston.

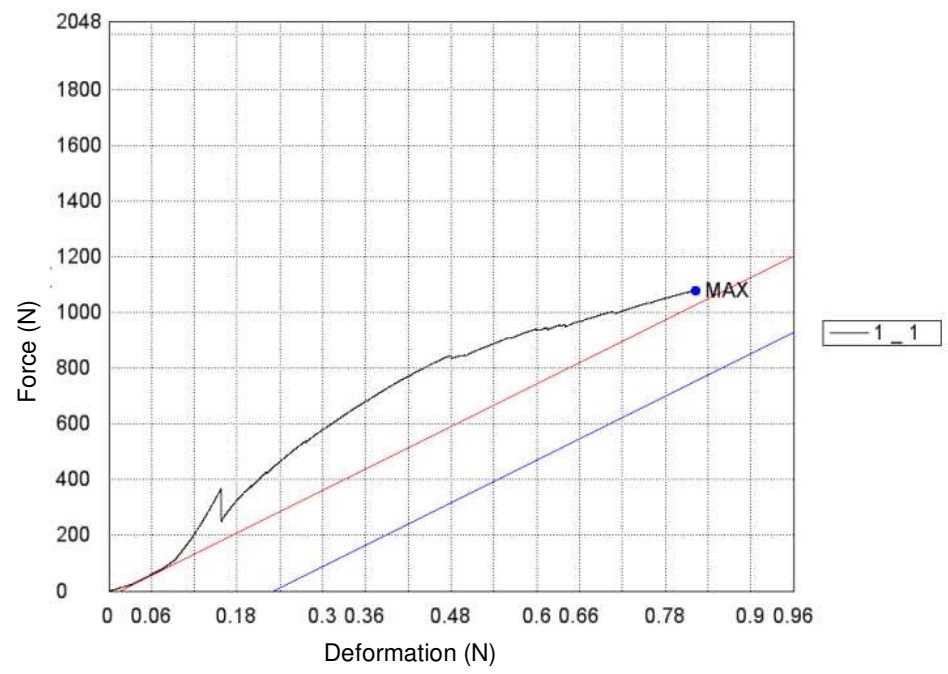

Fig. 2 Representative stress-strain graphic of metal-ceramic assembly where the first peak was considered as "chipping" (373 N) in the veneer ceramic. 


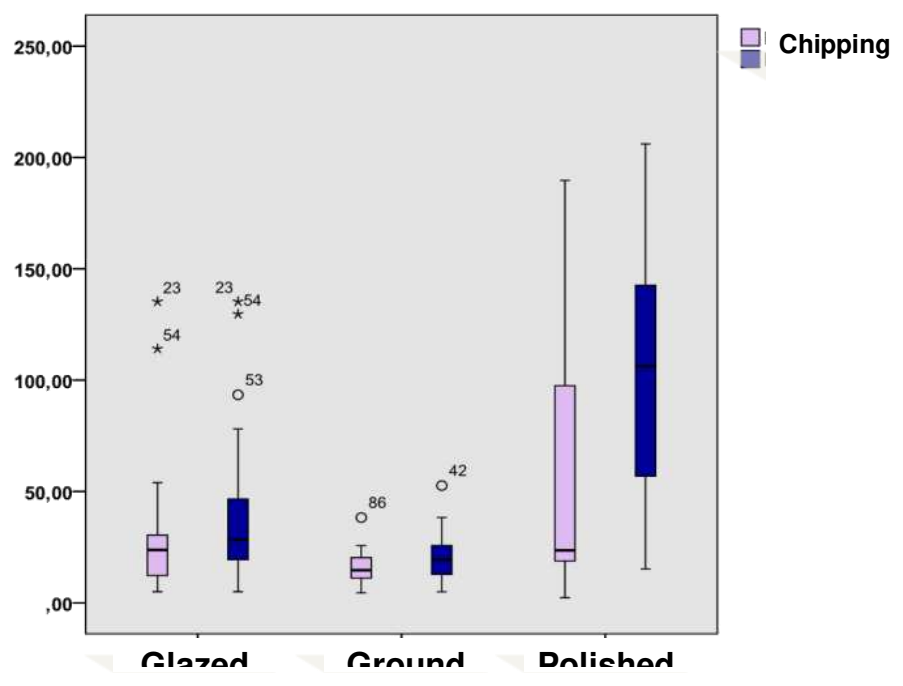

Fig. 3 Boxplot for fracture toughness of specimens regarding the surface treatment factor where highest values were obtained for the polished group.

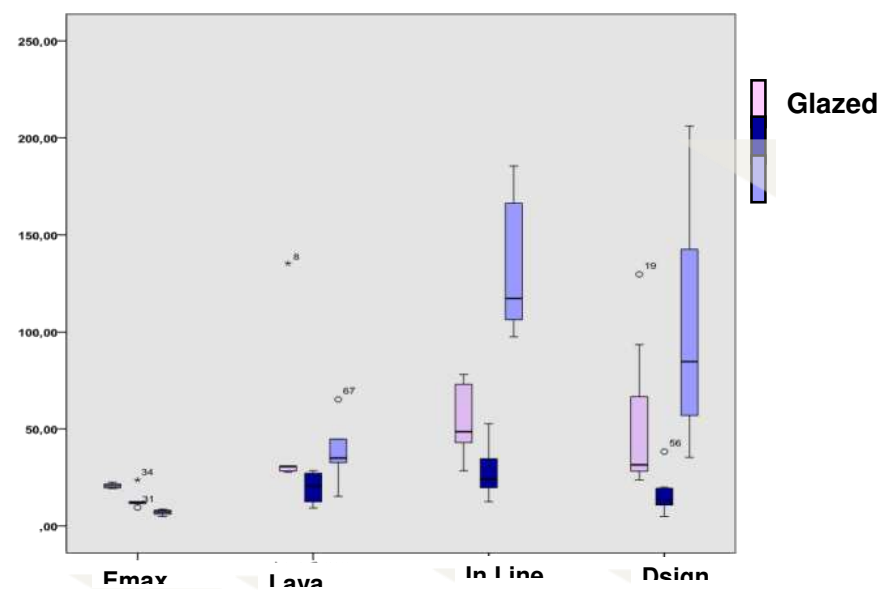

Fig. 4 Boxplot for fracture toughness of specimens regarding the veneering material where metal-ceramic assemblies showed higher values than all-ceramic groups. 


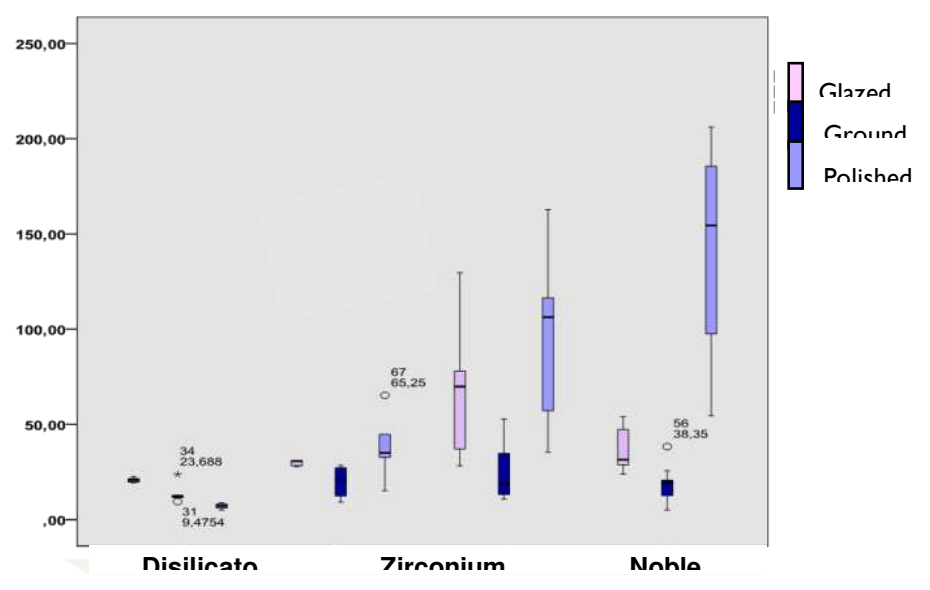

Fig. 5 Boxplot for fracture toughness of specimens regarding the framework material where metals showed higher values than all-ceramic groups.

23 